\title{
Editorial
}

\section{Active and Passive Flow Control of Turbomachines}

\author{
N. Sitaram, ${ }^{1}$ K. Funazaki, ${ }^{2}$ and Seyed G. Saddoughi ${ }^{3}$ \\ ${ }^{1}$ Department of Mechanical Engineering, Indian Institute of Technology Madras, Chennai 600 036, India \\ ${ }^{2}$ Department of Mechanical Engineering, Iwate University, Morioka, Iwate, Japan \\ ${ }^{3}$ Department of Aero-Thermal \& Mechanical Systems, GE Global Research, 1 Research Circle, Niskayuna, NY 12309, USA \\ Correspondence should be addressed to N. Sitaram; nsitaram@iitm.ac.in
}

Received 24 December 2012; Accepted 24 December 2012

Copyright (C) 2013 N. Sitaram et al. This is an open access article distributed under the Creative Commons Attribution License, which permits unrestricted use, distribution, and reproduction in any medium, provided the original work is properly cited.

Turbomachines are used in a wide range of applications. Increasing the efficiency and operating range of turbomachines reduces fuel consumption of gas turbine power plants and other applications. Over the years, many attempts have been made to achieve these objectives. The present special issue addresses these goals with special emphasis on active and passive flow control techniques.

This special issue compiles 7 original research articles that describe active and passive flow control techniques applied to different types of turbomachines. The theme for this special issue is set by J. P. Gostelow et al. They describe various types of vortices encountered in a transonic turbine nozzle blade passage. Active and passive control of these vortices is essential to improve the performance of turbines.

There are two more papers on control of turbine flows. The paper by R. Da Soghe et al. describes aerothermal analysis of a turbine casing impingement cooling system. T. Matsunuma and T. Segawa systematically varied the input voltage of plasma actuators to reattach the simulated boundary layer on the suction surface of a turbine at a low Reynolds number. The low-pressure turbine of aircraft gas turbine power plants operating at high altitudes operates at low Reynolds numbers. Losses in turbines operating at low Reynolds numbers increase rapidly due to large separation occurring on the suction surfaces of the turbine blades. Many researchers used dielectric barrier discharge (DBD) plasma actuators to actively control flow separation, tip clearance flows, and so forth in turbines and other turbomachinery components. The present paper by $\mathrm{T}$. Matsunuma and T. Segawa is a great addition to the available data that addresses the effects of input voltage to plasma actuators on flow control effectiveness.
Two papers describe active and passive flow control techniques applied to centrifugal compressors. A. Marsan et al. numerically investigated boundary layer suction technique applied to the radial diffuser of a transonic centrifugal compressor. They had presented an efficient control technique, which used a suction mass flow rate of $0.1 \%$ of global mass flow to increase the compressor operating range by $40 \%$. T. Hirano et al. experimentally investigated a passive nozzle injection system to control surge and rotating stall in high speed centrifugal compressors. They demonstrated optimum circumferential position of the injection nozzle.

S. Kyparissis and D. Margaris tested impellers with three different leading edge angles to optimize the leading edge angle to reduce cavitation development and enhance the performance of a centrifugal pump.

Active and passive flow control techniques are being extensively investigated in the primary components of turbomachinery. However to further improve the performance of turbomachinery, active and passive flow control techniques need to be applied to secondary components of turbomachines, such as seals. The last paper of the special issue by M. Zhang et al. addresses leakage flow characteristics of seals used in reactor coolant pumps. They had numerically shown that helical groove seal controls the leakage along the front surface of the impeller face due to its higher resistance than the circumferential grooved seal.

It is hoped that this special issue will provide useful information to wide readership from academia, industry and research establishments and inspire new and more efficient control techniques.

N. Sitaram

K. Funazaki

Seyed G. Saddoughi 

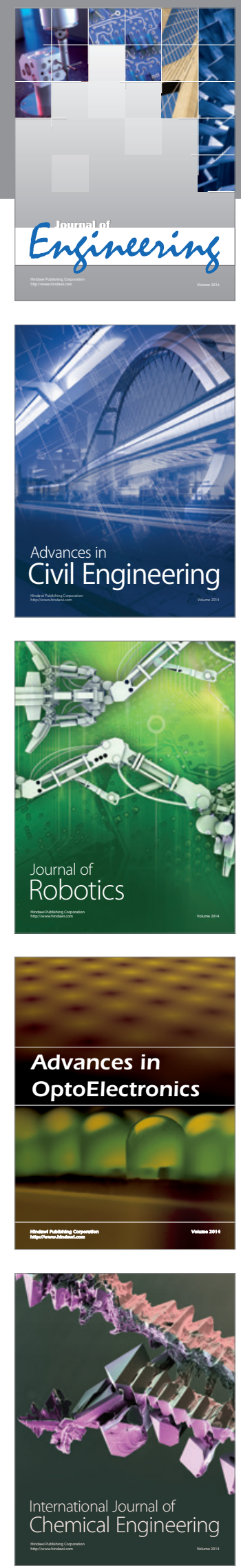

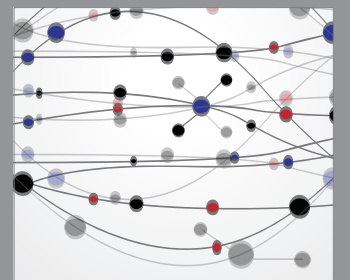

The Scientific World Journal
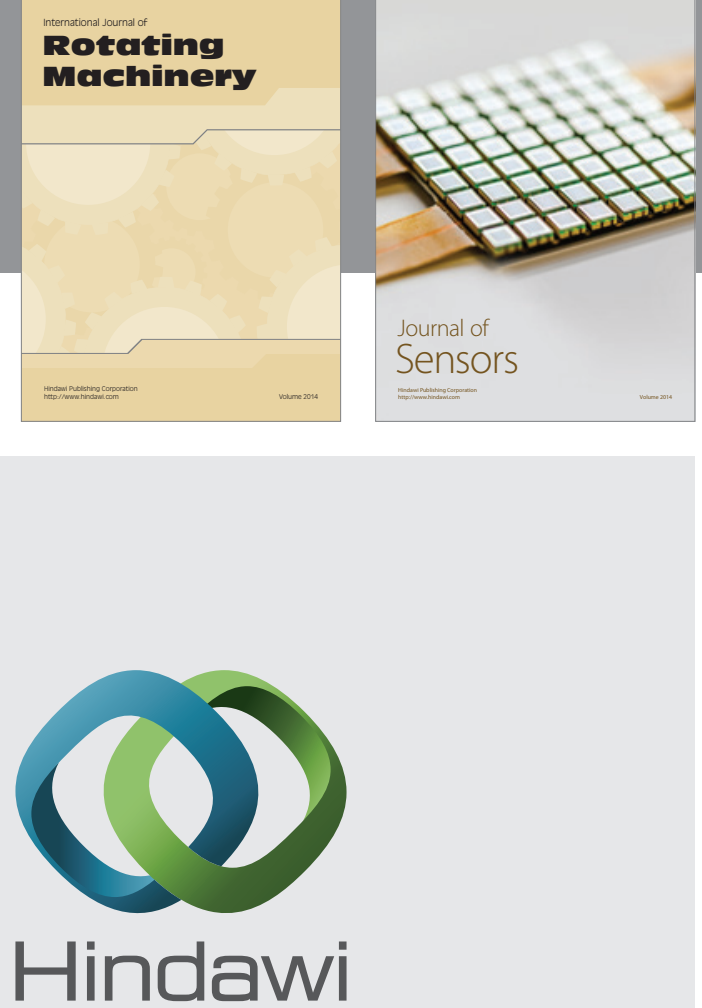

Submit your manuscripts at http://www.hindawi.com
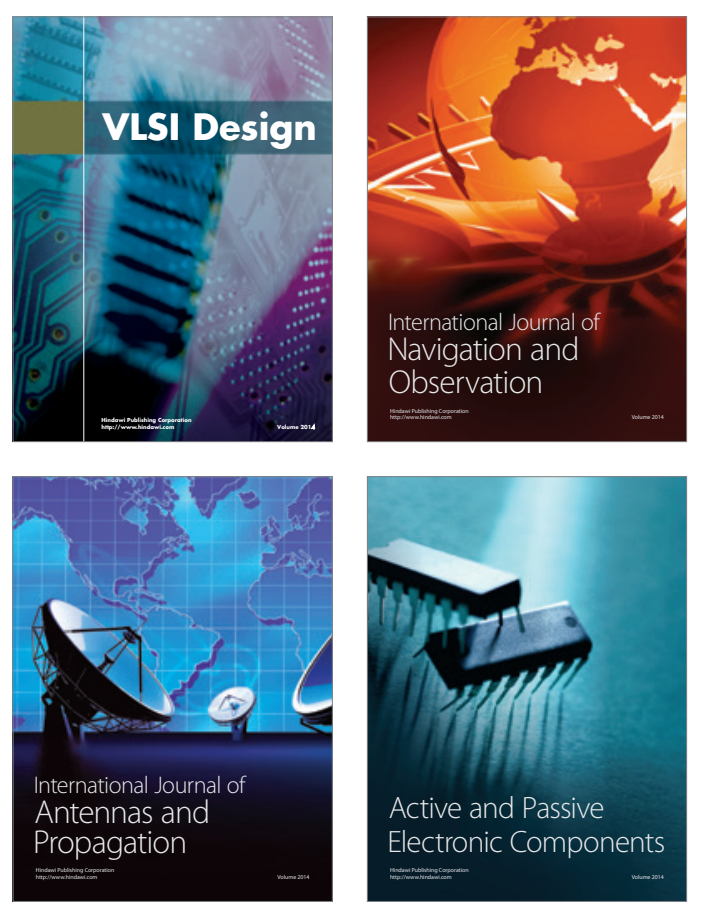
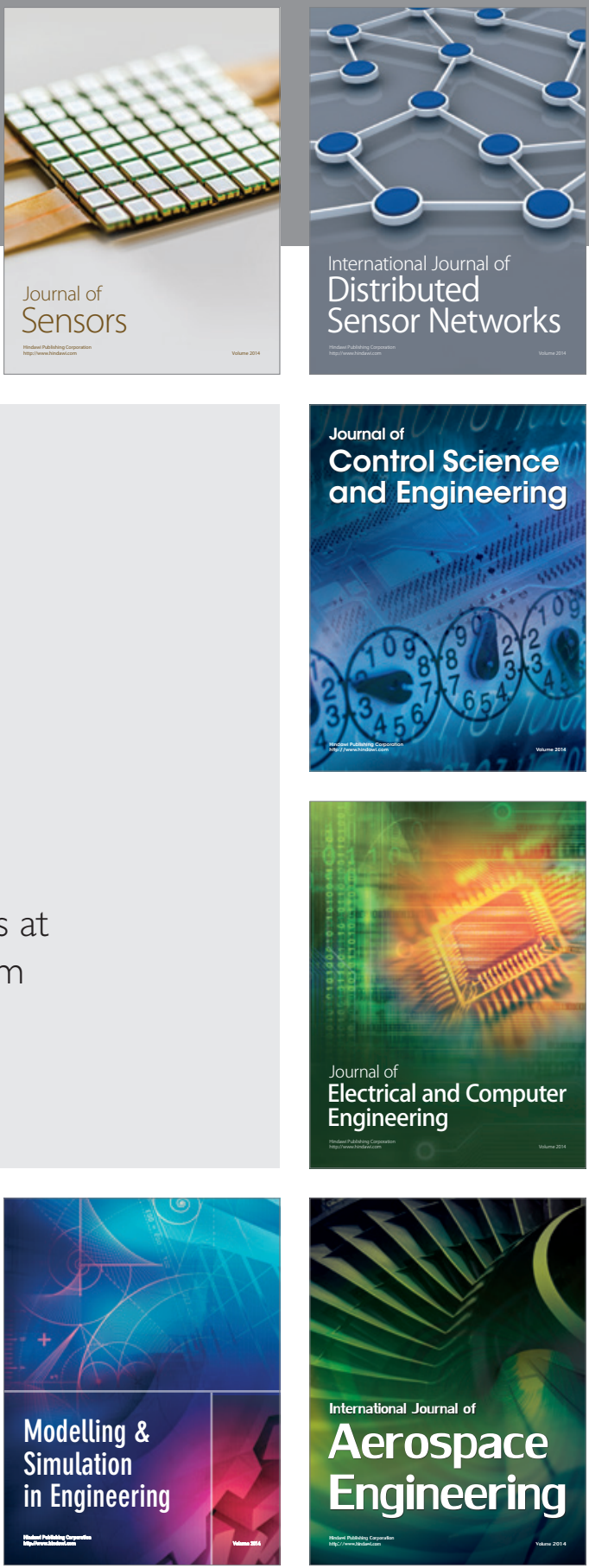

Journal of

Control Science

and Engineering
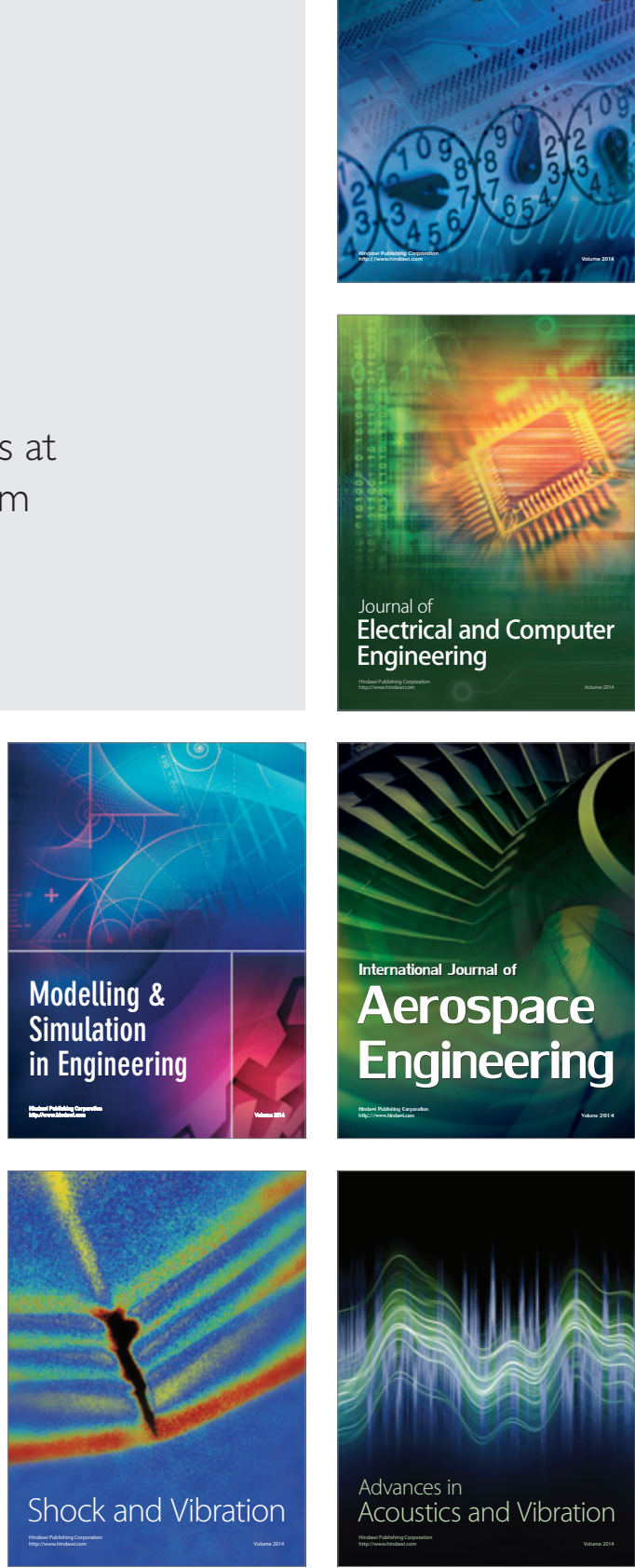